\title{
Blue rubber bleb naevus disease: an uncommon cause of gastrointestinal tract bleeding
}

\author{
M JENNINGS, P WARD, AND J L MADDOCKS \\ From the University Department of Pharmacology and Therapeutics, and Department of Radiology, Royal \\ Hallamshire Hospital, Sheffield
}

SUMMARY A 23 year old woman presented with facial pain, a right parotid tumour and iron deficiency anaemia. She had several cutaneous venous swellings and tumours with a similar appearance were found in the large bowel. Histological examination of the parotid tumour and angiography of the skin and gut lesions confirmed that they were venous in origin. The aetiology, classification, and complications of disorders of the venous system and the importance of using a tourniquet to examine the peripheral veins is discussed.

There is an ill defined group of conditions characterised by the coexistence of lesions in both the skin and the internal organs. For example, in blue rubber bleb naevus disease haemangiomas in the skin are associated with vascular polyps in the bowel. The latter may give rise to occult or frank gastrointestinal tract bleeding resulting in anaemia.

We have recently investigated a woman who presented with anaemia and a unilateral parotid swelling. She also had unusual skin lesions which seemed to arise from veins, and we found vascular tumours with similar appearances in the large bowel. This combination of abnormalities led to the diagnosis of blue rubber bleb naevus disease. Angiography confirmed that the skin and the bowel lesions were part of the venous system. This case illustrates firstly that careful examination of the skin of patients with anaemia may reveal the cause, and secondly how detailed investigation of vascular lesions helps in classification.

\section{Case history}

A 23 year old shop assistant initially visited her general practitioner because of heavy menstrual bleeding. He thought she was anaemic and prescribed oral iron supplements. Three years later, in

Address for correspondence: Dr $\mathbf{M}$ Jennings, University Department of Therapeutics, Royal Hallamshire Hospital, Glossop Road, Sheffield S10 2JF. Received for publication 14 April 1988.
1981, she went to see her dentist because of a painful lump on the right side of her face. The right parotid gland was intermittently swollen and tender, and a presumptive diagnosis was made of parotid duct obstruction caused by calculus. Sialography confirmed the presence of a stone but surprisingly it lay outside the duct. Subsequent surgical exploration of the gland revealed a plexus of veins containing three stones. This region was excised, and histological examination showed a vascular anomaly of angiomatous type in which thrombus had become organised into phleboliths (Fig. 1).

She was referred for a medical opinion and was found to be anaemic ( $\mathrm{Hb} 8.7 \mathrm{~g} / \mathrm{dl})$. She denied any

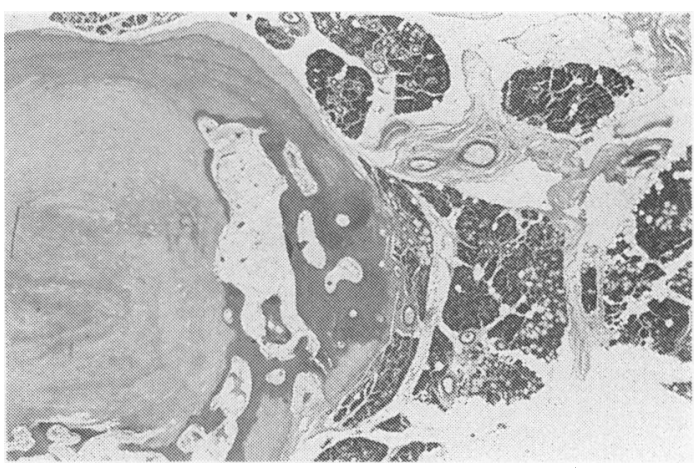

Fig. 1 Section of parotid gland showing angioma. 


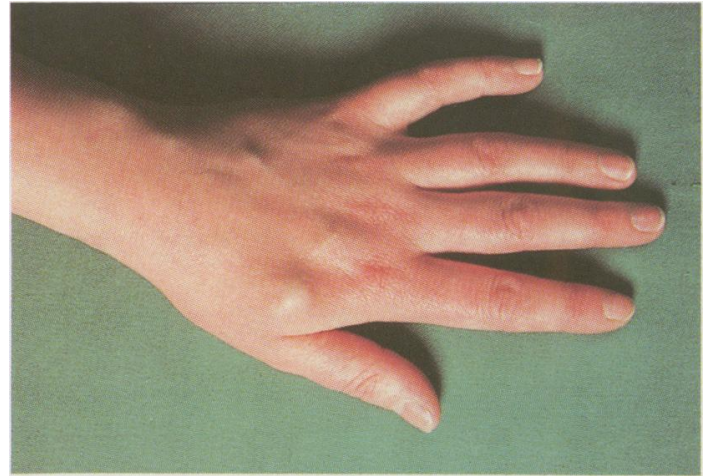

Fig. 2 Venous varicosity on the dorsum of the left hand, with smaller lesions on the ulnar aspect.

blood in her stools, haematemesis, or melaena. Her periods were regular but heavy. There was no history of excessive bleeding or bruising. She had stopped taking the iron tablets prescribed by her doctor after only a few months. Her father had died aged 53 years from a brain haemorrhage, and she has a sister with epilepsy. Careful examination of her skin revealed an irregular venous varicosity, $1.5 \mathrm{~cm}$ in diameter, on the dorsum of the left hand (Fig. 2). Smaller similar lesions were found on the tongue (Fig. 3), soft palate (Fig. 4), and labia. When a tourniquet was applied to each forearm, multiple globular venous swellings became visible on the skin surface and the varicosity on her hand became much more prominent. A port wine stain was found on the nape of her neck (Fig. 5).

The blood film showed a microcytic hypochromic picture, and three specimens of faeces were positive for occult blood. A barium enema showed two small polyps, one at the splenic flexure (Fig. 6), and the other just proximal to the hepatic flexure. At colonoscopy two vascular polyps were seen, each $1 \mathrm{~cm}$ in diameter, the first in the rectum, and the second at the splenic flexure. There were three other tiny

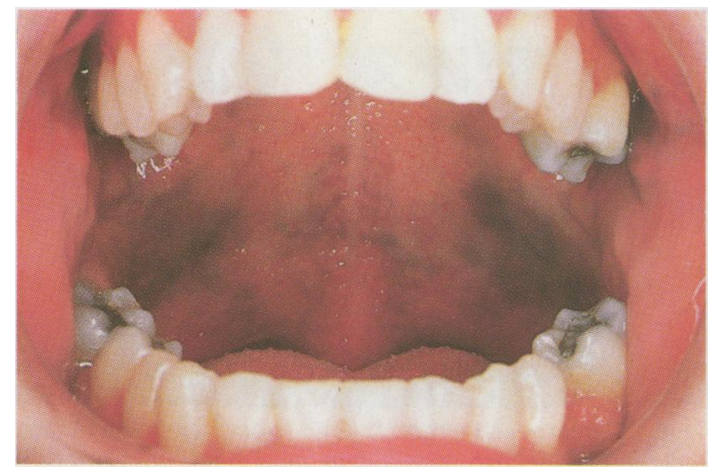

Fig. 4 Lesions on the soft palate.

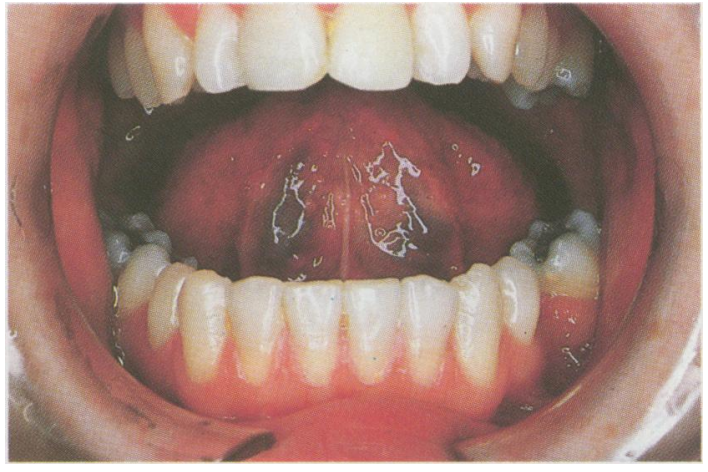

Fig. 3 The undersurface of the tongue.

similar lesions in the descending colon. Initially the proximal half of the transverse colon and the ascending colon were not visualised because the patient complained of pain. At a subsequent examination, however, the tumour at the hepatic flexure was seen. The lesions were not biopsied because of their very vascular appearance and thus the fear of serious haemorrhage. At gastroscopy, the stomach and duodenum were normal. Plain radiographs revealed phleboliths on both sides of the face, in the neck, and the lung apices (Fig. 7). Arteriography with selective injection of the mesenteric vessels showed a collection of venous spaces in the region of the hepatic flexure (Fig. 8). In view of the family history of brain haemorrhage, cerebral arteriography was undertaken to exclude an intracranial vascular anomaly, but none was seen. Venography of the forearm vessels showed widespread tiny venous aneurysms, and a larger plexiform lesion (Fig. 9) which corresponded to the venous swelling seen on the skin.

She was transfused with blood but she also required oral iron supplements because of continued occult bleeding from the bowel. Apart from occasional pain and swelling over the right cheek she

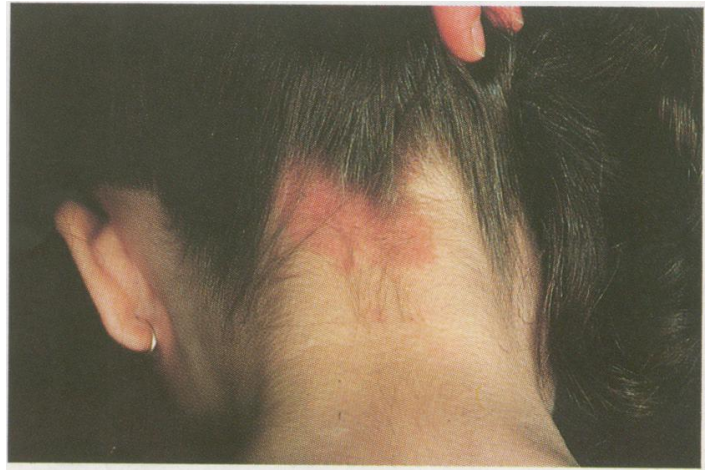

Fig. 5 Port wine stain on the neck. 


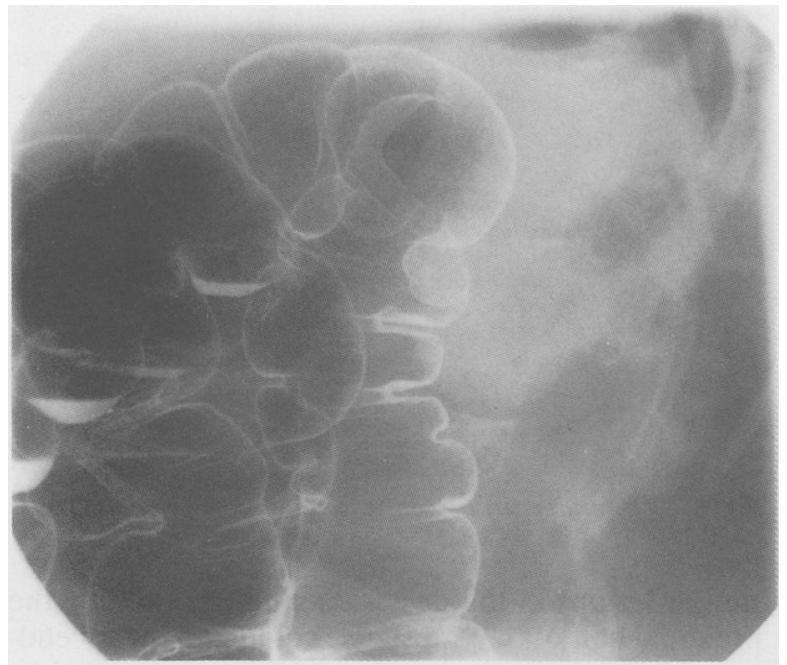

Fig. 6 Double contrast barium enema showing a small polyp at the splenic flexure.

remained well for almost three years. She then passed three melaena stools and the haemoglobin fell to $6 \cdot 1 \mathrm{~g} / \mathrm{dl}$. We referred her to Dr N Krasner, Walton Hospital, Liverpool, for laser treatment of the colonic tumours. This was started in July 1987 after blood transfusion and her haemoglobin is now stable.

\section{Discussion}

Blue rubber bleb naevus disease is an uncommon condition in which haemangiomas in the skin are associated with intestinal haemorrhage from similar lesions in the gut.' It was probably first reported by Gascoyen $^{2}$ in 1860 . He described a man who pre-

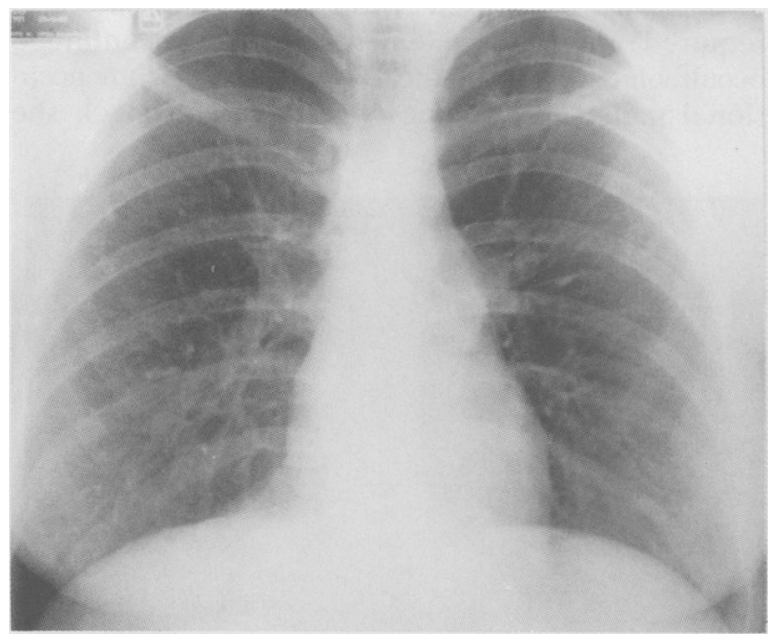

Fig. 7 Chest radiograph. Small calcified opacities at the apices.

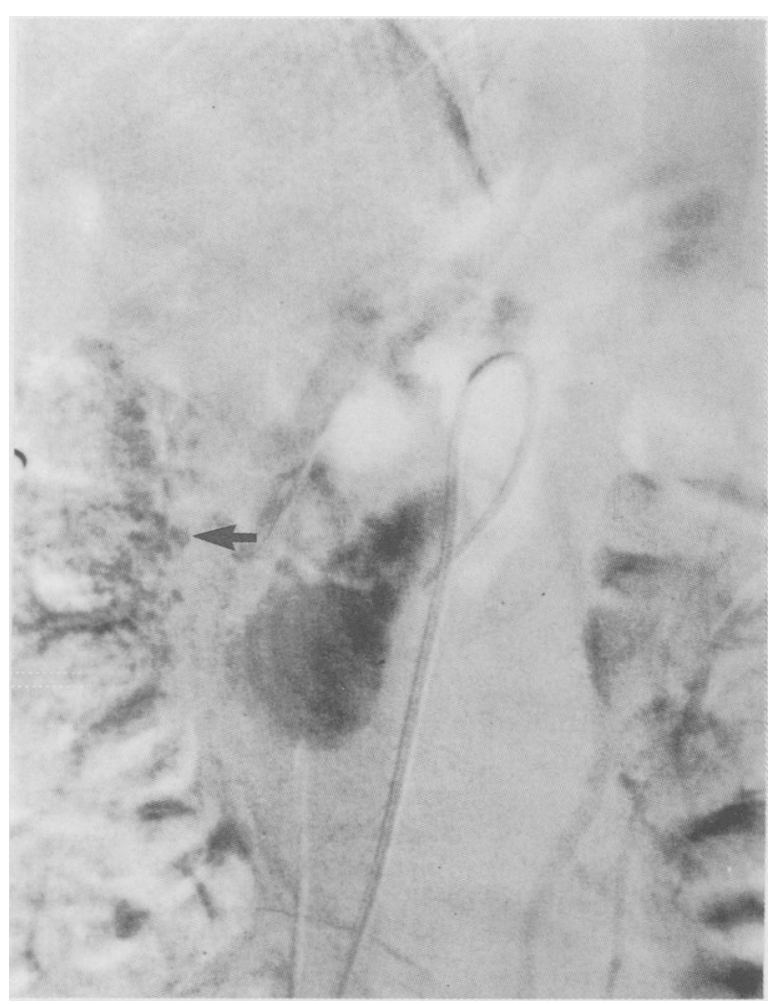

Fig. 8 Subtraction film of superior mesenteric artery angiogram showing a collection of venous spaces in the wall of the colon $(->)$.

sented with a congenital tumour of the parotid, and who died from suffocation after gross enlargement of the tumour. At necropsy there were cutaneous naevi distributed widely over the skin surface, with similar

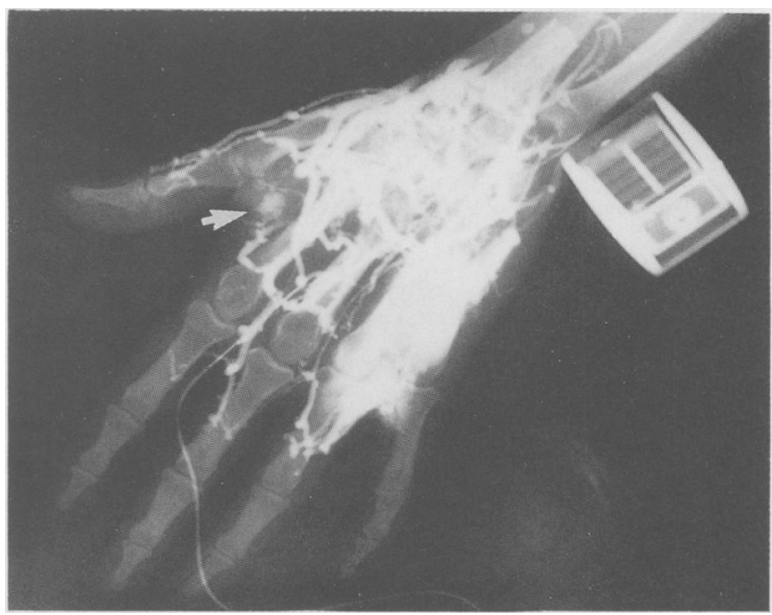

Fig. 9 Forearm venography shows widespread varicosities, the largest $(->)$ corresponding to the skin lesion shown in Fig. 2. 
lesions 'studding the surface of the intestines'. The parotid tumour was composed of tortuous and dilated blood vessels many of which contained phleboliths. There have been about 20 further reports of the syndrome. The term 'blue rubber bleb naevus' was introduced by Bean $^{3}$ in 1958 because the cutaneous lesions 'have the look and feel of rubber nipples, are compressible and refill fairly promptly from their rumpled and compressed state'.

The principal sites of involvement are the skin, and the gut $^{\text {th }}$ including the oral mucous membrane,? although lesions in the liver, lung, and skeletal muscle have been found at necropsy. ${ }^{8}$ Apart from Gascoyen's original description there have been no other reports of salivary gland involvement. Walshe et $a l^{4}$ ascribed the occurrence of haematuria and epistaxis in their patient to bladder and upper respiratory tract involvement respectively, but their investigations failed to show the presumptive vascular tumours. Our patient was found to have lesions in the skin, large bowel, and parotid gland. We presume that the phleboliths seen on the chest radiographs indicate involvement of the lungs also. The appearances of cutaneous naevi in this condition may not be uniform. Bean ${ }^{3}$ described three morphological types of lesion: large cavernous angiomas, blue rubber blebs, and an irregular blue mark of the skin. The number and distribution of lesions on the body surface is also variable.

Naevi tend to appear during the first few years of life, and may subsequently enlarge and give rise to various complications. Some patients have complained of painful lesions. ${ }^{7810}$ This may be because of the contraction of smooth muscle fibres surrounding the vascular tumours." Excessive sweating from overlying skin has been accounted for by the close anatomical association between naevi and sweat glands. '2 Our patient has not noticed local sweating, but did experience pain over the facial swelling. This may have been because of stretching of the capsule of the parotid gland rather than having arisen directly from the angioma.

Thrombosis and secondary calcification may occur within the naevi. In our patient we found thrombosis and phlebolith formation in the parotid tumour and calcification on the chest film. Because the vascular polyps seen through the colonoscope did not fill with contrast during angiography we think that they also may have thrombosed. An association with pulmonary hypertension has been suggested, ${ }^{1.3}$ possibly arising through in situ thrombosis and obliteration of the pulmonary vascular bed. A further potential problem is platelet consumption which has been described in association with single large cavernous haemangiomas. ${ }^{14}$

Blue rubber bleb naevus disease has been seen in successive generations, ${ }^{13}$ and an autosomal dominant mode of inheritance postulated. ${ }^{310} 15 \mathrm{We}$ can find no evidence of the condition in the first degree relatives of our patient. Her father died of a brain haemorrhage but he did not have skin lesions, and we think it unlikely that he had blue rubber bleb naevus disease. The commonest mode of presentation is with gastrointestinal tract bleeding from vascular tumours in the large $^{+5}$ and small bowel. ${ }^{61617}$ The skin lesions are usually obvious, although in our patient the smaller ones were visible only after the application of a tourniquet.

In view of the appearance of the cutaneous lesions and the pattern of organ involvement we think that our patient has blue rubber bleb naevus disease. She does not have the telangiectasia on the face, lips, and nails characteristic of hereditary haemorrhagic telangiectasia. Although she has a port wine stain on her neck, there is no underlying intracranial haemangioma such as one might expect if she had either Sturge-Weber ${ }^{1 \mathrm{x}}$ or Von-Hippel Lindau disease. ${ }^{19}$ We felt that as we had the histology of the parotid gland, further biopsies of either the skin or the bowel lesions were unnecessary and possibly hazardous. We considered detailed radiological investigation to be essential, however, to determine the morphological site and anatomical distribution of the abnormalities. We were particularly concerned about the possibility of an intracranial lesion. This may have required treatment, and would have prompted counselling with regard to the risk of bleeding in future pregnancy.

Selective mesenteric angiography revealed a collection of venous spaces at the hepatic flexure. The other polyps in the colon were not seen possibly because of in situ thrombosis. The angiographic appearance of the cutaneous lesions in blue rubber bleb naevus disease has not, so far as we are aware, been previously documented. We have demonstrated venous varicosities in the forearms which corresponded to the observed skin lesions, and we therefore think that blue rubber bleb naevus disease should be regarded as a disorder of the venous system.

The problem of classifying venous disorders has been approached in different ways. Lea Thomas and Andress $^{21}$ divided venous dysplasias of the limbs into two groups on the basis of their angiographic appearances: phlebectasia, in which the principal abnormality is dilated venous trunks, and venous angiomas, which consist largely of cavernous spaces. Malan and Puglionisi ${ }^{21}$ adopted an embryological approach and defined four categories; phlebectasia, phlebangioma, phlebangiomatosis, and combinations of the three further divided for site and extent. The lesions of blue rubber bleb naevus disease 
Table Distribution of lesions

\begin{tabular}{lll}
\hline $\begin{array}{l}\text { Type of } \\
\text { Lesion }\end{array}$ & Cutaneous & Visceral \\
\hline Capillary & $\begin{array}{c}\text { Capillary angioma } \\
\text { ('strawberry naevus') } \\
\text { Naevus flammeus } \\
\text { ('port-wine stain') }\end{array}$ & $\begin{array}{c}\text { Osler-Weber-Rendu } \\
\text { (GI tract and lung) } \\
\text { Sturge-Weber (Meninges) }\end{array}$ \\
& & $\begin{array}{c}\text { Cobb (Spinal cord) } \\
\text { Von Hippel-Lindau } \\
\text { (Central nervous system) }\end{array}$ \\
Venous & Cavernous angioma & $\begin{array}{c}\text { Gorham } \\
\text { Maffuci }\end{array}$ \\
& & Blue rubber bleb naevus \\
(GT tract and lung)
\end{tabular}

probably correspond to the venous angiomas or phlebangiomatosis described by these authors.

There are clinical syndromes in which dilatation of major veins is the principal abnormality. The Klippet-Trenauney syndrome ${ }^{22}$ for example, is the triad of varicose veins, limb hypertrophy, and cutaneous haemangioma confined to one extremity. Parkes-Weber ${ }^{23}$ described a similar condition complicated by an A-V fistula. Involvement of the viscera is not found in these conditions.

From the clinical standpoint the classification of such syndromes is ill defined. There are several conditions in which vascular lesions in the skin are associated with similar lesions in other organs. The latter may be: the meninges, in Sturge-Weber; the brain and retina in von-Hippel Lindau; the spinal cord as described by $\mathrm{Cobb}^{24}$; and the skeleton by Gorham $^{25}$ and Maffucci $^{26}$; or the gut and lung in Osler-Weber-Rendu disease. Blue rubber bleb naevus disease is clearly a disorder which shares this pattern of cutaneous and visceral involvement. In this respect it most closely resembles Osler-WeberRendu disease, but the two may be distinguished by the very different appearance of the skin lesions. It is of interest that in both conditions abnormalities may also be found in the lungs, which of course share their embryological origins with the foregut. We have attempted a simple classification of these disorders (Table).

\section{References}

1 Dennis DJ, Dobson RL, McGuire J. In: Clinical dermatology. New York: Harper and Row, 1983: 7-68.

2 Gascoyen GG. Case of nacvus involving the parotid gland and causing death from suffocation: naevi of the viscera. Trans Pathol Soc London 1860; 11: 267.
3 Bcan WB. Vascular spiders and related lesions of the skin. Springfield, Ill: Charles C Thomas, 1958.

4 Heycock JB, Dickinson PH. Haemangiomata of the intestinc. Br Med J 1951; 1: 620 .

5 Holman CC. Haemangioma of the sigmoid colon. $\mathrm{Br} \mathrm{J}$ Surg 1948; 36: 210.

6 Rickham PP. A case of haemangiomatosis of the small intestinc. Br J Surg 1952; 39: 462.

7 Fretzin DF, Potter B. Blus rubber bleb naevus. Arch Intern Med 1965; 116: 924-5.

8 Rice JS, Fischer DS. Blue rubber bleb naevus syndrome. Arch Dermatol 1962; 86: 503-11.

9 Walshe MM, Evans CD, Warin RP. Blue rubber bleb naevus. Br Med J 1966; 2: 931.

10 Berlyne GM, Berlyne N. Anaemia due to blue rubber bleb naevus disease. Lancet 1960; 2: 1275.

11 Fine RM, Derbes VJ, Clark, WH. Blue rubber bleb naevus. Arch Dermatol 1961; 84: 802-5.

12 Archer BWC. Multiple cavernous angiomata of the sweat ducts associated with hemiplegia. Lancet 1927; ii: 595-6.

13 Talbot S, Wyatt EH. Bluc rubber bleb naevi. $\mathrm{Br} J$ Dermatol 1970; 82: 37-9.

14 Kassabach HH. Merritt KK. Capillary haemangioma with extensive purpura. Am J Dis Child 1940; 59: 1063.

15 Pruzenski W. Intestinal and cutaneous hacmangiomatosis. Am J Dig Dis 1963; 8: 200-5.

16 Morris SJ, Kaplan SR, Ballan K. Tedesco FJ. Blue rubber bleb naevus syndrome. JAMA 1978; 239: 18887-8.

17 McClure RD, Ellis SW. Haemangiomata of the intestine. Am J Surg 1930; 10: 241.

18 Sturge WA. A case of partial epilepsy apparently due to a lesion of one of the motor centers of the brain. Trans Clin Soc London 1879; 12: 112.

19 Lindau A. Studien über kleinhirncysten Bau, Pathogenese und Bezichungen zur Angiomatosis Retinae. Acta Pathol Microbiol Scand 1926; suppl: 1-128.

20) Lea Thomas ML. Andress MR. Angiography in venous dysplasias of the limbs. Am J Roentgenol 1971; 113: 72273.

21 Malan E, Puglionisi A. Congenital angiodysplasias of the extremities I. Generalities and classification; venous dysplasias. J Cardiovasc Surg 1964; 5: 87-130.

22 Klippel M, Trenauney P. Nevus variqueux osteohypertrophique. Arch Gen Med 1900; 3: 641-72.

23 Parkes-Weber F. Angioma formation in connection with hypertrophy of the limbs and hemi-hypertrophy. Br J Dermatol 1907; 19: 231-5.

24 Cobb S. Haemangioma of the spinal cord associated with skin naevi of the same metamere. Ann Surg 1915; 62: 641-9.

25 Gorham LW, Wright AW, Schultz HH, Maxon FC. Disappearing bones; a rare form of massive osteolysis. Am J Med 1954: 17: 674.

26 Carlton A, Elkington JStC, Greenfield JG, Robb-Smith AHT. Maffucci's syndrome. $Q J$ Med 1942; 11: 203-28. 